\title{
The Evaluation of Steel Frame Structures with Viscoelastic Dampers
}

\author{
Ali Khoshraftar
}

\begin{abstract}
This paper is focused on the advantages of viscoelastic dampers (VED) to be used as energy-absorbing devices in buildings. The properties of VED are briefly described. The analytical studies of the model structures exhibiting the structural response reduction due to these viscoelastic devices are presented. Computer simulation of the damped response of a multi-storey steel frame structure shows significant reduction in floor displacement levels.
\end{abstract}

Index Terms-Dampers, seismic evaluation, steel frames, viscoelastic.

\section{INTRODUCTION}

Viscoelastic dampers are energy dissipation devices of passive type, frequently used to mitigate excessive vibration of structures due to winds or earthquakes. The properties of viscoelastic dampers, such as the possibility of energy dissipation and stiffness, are frequency and temperature dependent and are commonly defined in terms of experimentally obtained storage and loss modules.

For years viscoelastic dampers have been widely used not only to improve residential comfort in strong winds but also to enhance structural safety against large earthquake ground motion. There are many examples, such as World Trade Center in New York and Columbia Center in Seattle, USA, where viscoelastic dampers were applied successfully to enhance the structural performance against dynamic loads [1], [2].

Many researches have been conducted to derive analytical models for VED and to verify the effect on structural control through experiments [3]-[6]. Previous studies showed that VED can increase structural damping significantly, which brings the decrease of structural responses, such as displacement and absolute acceleration. The results of these studies also indicated that the performance of VED depends on factors such as excitation frequency and environmental temperature, and so the effects of VED should be evaluated by considering these factors. Zhang et al. proposed a sequential procedure for optimally placing VED based on the concept of degree of controllability [1]. Lee et al. determined the location and the size of VED by using pole assignment method [7]. These studies showed that placing VED at the position with the largest inter-storey displacement is most effective.

In this presentation, the influence of viscoelastic dampers

Manuscript received November 28, 2015; revised February 28, 2015

Ali Khoshraftar is with the Department of civil Engineering, Ahvaz Branch, Islamic Azad University, Ahvaz, Iran (e-mail: Khoshraftar@iauahvaz.ac.ir). on the reduction of seismic response of various structures is investigated by analytical studies.

\section{PROPERTIES OF VisCOElASTIC DAMPERS}

The properties and damping mechanism of VED are briefly presented below. For detailed discussions on VED, the reader is directed to References [2], [8] and [9].

As their name implies, viscoelastic materials exhibit combined features of elastic solid and viscous liquid when undergoing deformation, i.e. they will return to their original shape after one cycle of deformation but with a certain amount of energy lost as heat.

This is evident by observing the stress-strain and force-extension relationships, as illustrated in Fig. 1 and Fig. 2 , when undergoing harmonic deformation. Although the stress amplitude is proportional to that of strain, stress leads strain by a phase angle $\delta$ and can be expanded into two components with the same frequency, one in phase with strain and the other $90^{\circ}$ out of phase. Thus, if strain is given as

$$
\gamma=\gamma_{0} \sin \omega t
$$

then stress can be expressed as

$$
\sigma=\sigma_{0} \sin (\omega t+\delta)
$$

where $\gamma_{0}$ is the strain amplitude and $\sigma_{o}$ is the stress amplitude. When shear is considered, the relationship between shear stress and strain is given by

$$
\sigma=\gamma_{0}\left[G^{\prime}(\omega) \sin \omega t+G^{\prime \prime}(\omega) \cos \omega t\right]
$$

where $G^{\prime}=\sigma_{0} \cos \frac{\delta}{\gamma_{0}}$, is the shear storage modulus and $G^{\prime \prime}=\sigma_{0} \sin \frac{\delta}{\gamma_{0}}$ is the shear loss, and both are functions of frequency $\omega$.

After one cycle of harmonic deformation, the plot of extension against force forms a hysteretic loop as shown in Fig. 2. The area encompassed by this loop equals the energy dissipated as heat in one cycle and is related to $G^{\prime \prime}$ and $\gamma_{\circ}$ by for a unit volume of the VE material. Thus, adding VE dampers to structures has two effects, namely, an added energy dissipation and an adjustment of the system stiffness.

$$
E_{0}=\int_{0}^{2 \pi \omega} \sigma\left(\frac{d \gamma}{d t}\right)^{2} d t=\pi \gamma_{0}^{2} G^{\prime \prime}(\omega)
$$

Viscoelastic materials used in structural applications are usually copolymers or glassy substances that dissipate energy 
through shear deformation. A typical VE damper, which consists of VE layers bonded with steel plates, is shown in Fig. 3. When mounted in a structure, shear deformation and hence energy dissipation takes place when structural vibration induces relative motion between the outer steel flanges and the center plates. Significant advances in research and development of VE dampers, particularly for seismic applications, have been made in recent years through analyses and experimental tests [10]-[12].

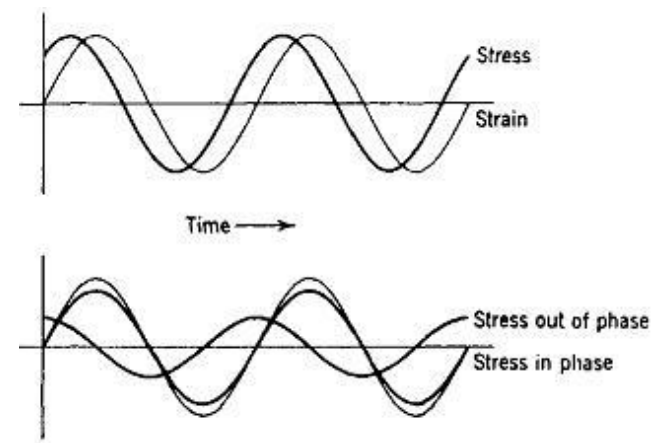

Fig. 1. Stress-strain relationship.

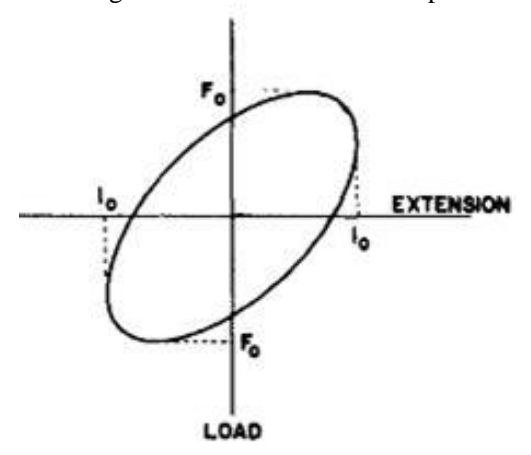

Fig. 2. Extension-load curve.

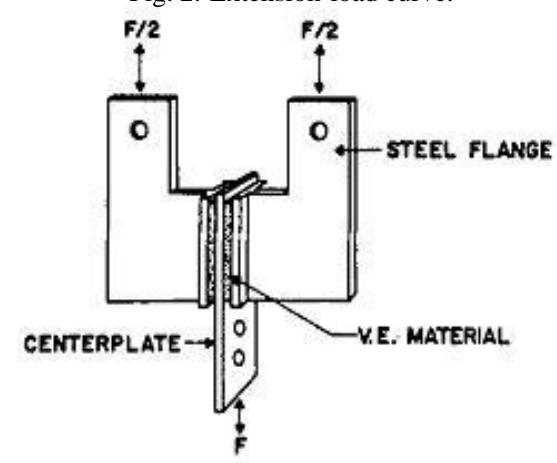

Fig. 3. Typical VED construction.

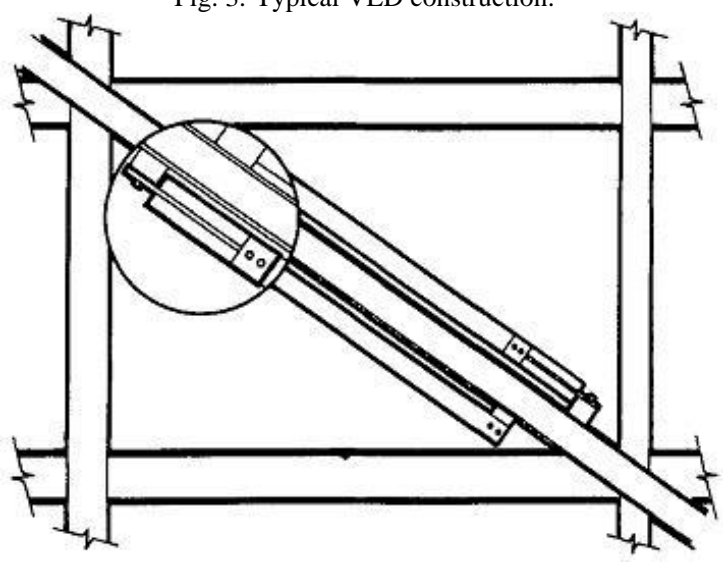

Fig. 4. Example of VED location on structure.

There are several possible VE damper designs. The type we have chosen to study is shown in Fig. 3. This damper consists of two $V E$ layers of uniform thickness; they are confined by three steel plates and will experience nearly pure shear when the steel plates move with respect to each other. If the total volume of the $V E$ material is $V$, the energy dissipated in one cycle is

$$
E_{d}=E_{0} V=\pi \gamma_{0}^{2} G^{\prime \prime}(\omega) V
$$

For a given $V E$ material and damper dimensions, $V$ and $G^{\prime \prime}(\omega)$ are constants (under a certain frequency).

Damping is achieved when dampers are located between two points of a structure or between structure and support where significant relative displacements are present. VE dampers in the Columbia Center, for example, are located on the main diagonals of its frame structure. Fig. 4 gives a typical VE damper construction and its location in building applications.

\section{ANALYTICAL INVESTIGATION}

In this study, three 2D-frame models were used for moment frames having the number of stories 5, 10, 15 as shown in Fig. 5. The structures were designed using SAP2000 software.

A series of standard I-shaped profiles were used to model bending frame including beam and column. So, the value of dead load for all stories is equal to $23 \mathrm{kN} / \mathrm{m}$, while the amounts of live loads for the stories are $8 \mathrm{kN} / \mathrm{m}$. Also to perform nonlinear dynamic analyses, OpenSees 2.4 software was used.

The Open System for Earthquake Engineering Simulation (OpenSees) is being developed by the Pacific Earthquake Engineering Research Center (PEER) for the research and professional communities and it is open-source "object-oriented framework for finite element analysis". The goal of OpenSees is to improve modeling and computational simulation in earthquake engineering through open-source development. Structures in OpenSees can be modeled in 2D or 3D including linear damping and may include elements with degrading stiffness.

All analyses of the research are of time history analysis type done using OpenSees software. Seven earthquake records were used in time history analyses according to Table I.

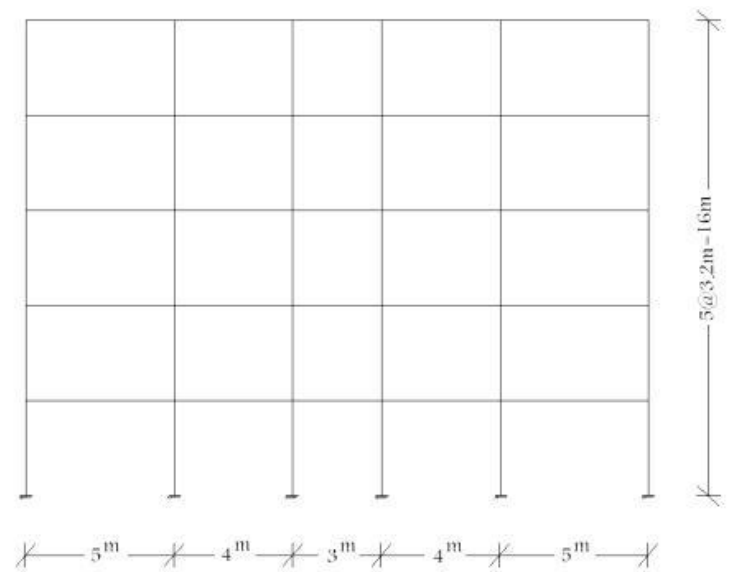

Fig. 5. Sample frame without added VE damper. 
TABLE I: FEATURES OF THE SELECTED EARTHQUAKES

\begin{tabular}{lll}
\hline \hline Earthquake & Duration $(\mathrm{sec})$ & PGA $(\mathrm{g})$ \\
\hline Landers & 49.98 & 0.721 \\
Loma Prieta & 39.57 & 0.204 \\
Manjil & 35.4 & 0.505 \\
New Zealand & 26.98 & 0.292 \\
Northridge & 39.98 & 0.633 \\
Park Field & 30.32 & 0.293 \\
Tabas & 32.82 & 1.0 \\
\hline \hline
\end{tabular}

The seismic response of 5-story model, 10-story model, and 15-story model with the same arrangement of viscoelastic damper subjected to real earthquake ground motion is investigated as shown in Fig. 6.

The response is investigated under different earthquake ground motions as represented in Table I.

In this report Comparative study between Buildings with dampers, without dampers has been done for seismic response like top floor displacement (top drift).

The effects of added damping in a structure subjected to earthquake transients is depicted in the results obtained from OpenSees Non-linear time history analysis provided in Table II to Table IV and Fig. 7 to Fig. 9.
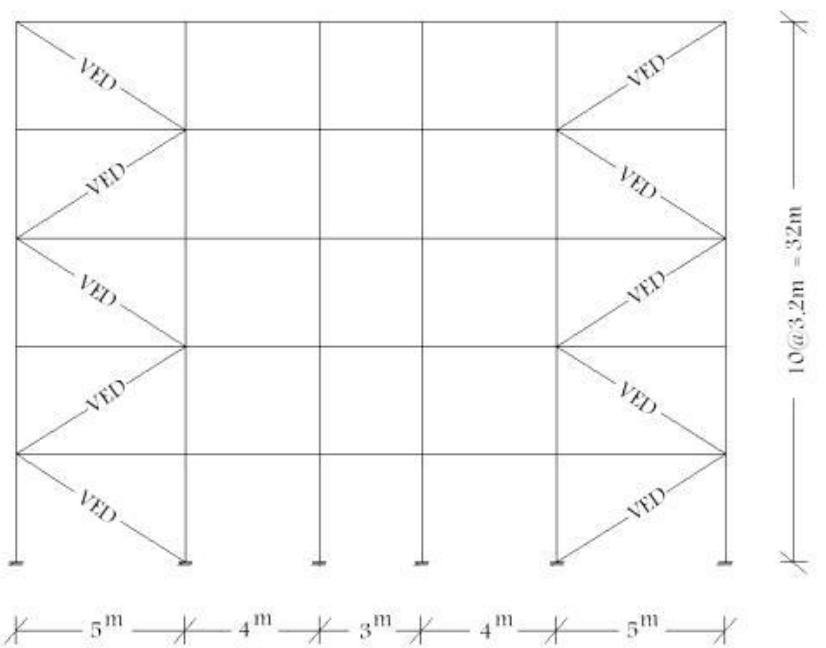

Fig. 6. Sample frame with added VE damper.

TABLE II: THE MAXIMUM RESPONSE FOR 5-STORY MODEL (MM)

\begin{tabular}{lll}
\hline \hline Earthquake & Bare frame & Added with VED \\
\hline Landers & 66.9 & 47.1 \\
Loma Prieta & 301.87 & 226.07 \\
Manjil & 173.68 & 82.6 \\
New Zealand & 129.4 & 75.96 \\
Northridge & 276.2 & 178.49 \\
Park Field & 112.94 & 83.97 \\
Tabas & 151.1 & 93.35 \\
\hline \hline
\end{tabular}

TABLE III: THE MAXIMUM RESPONSE FOR 10-STORY MODEL (MM)

\begin{tabular}{lll}
\hline \hline Earthquake & Bare frame & Added with VED \\
\hline Landers & 267.8 & 126.3 \\
Loma Prieta & 1097 & 784.6 \\
Manjil & 273.4 & 200.6 \\
New Zealand & 174.8 & 107.3 \\
Northridge & 268.69 & 187.13 \\
Park Field & 209.23 & 146.64 \\
Tabas & 319.1 & 266.1 \\
\hline \hline
\end{tabular}

TABLE IV: THE MAXIMUM RESPONSE FOR 15-STORY MODEL (MM)

\begin{tabular}{lll}
\hline \hline Earthquake & Bare frame & Added with VED \\
\hline Landers & 250.8 & 170.27 \\
Loma Prieta & 1902.7 & 1283.14 \\
Manjil & 271.7 & 195.2 \\
New Zealand & 199.38 & 152.58 \\
Northridge & 243.54 & 156.99 \\
Park Field & 187.07 & 125.01 \\
Tabas & 967.1 & 622.11 \\
\hline \hline
\end{tabular}

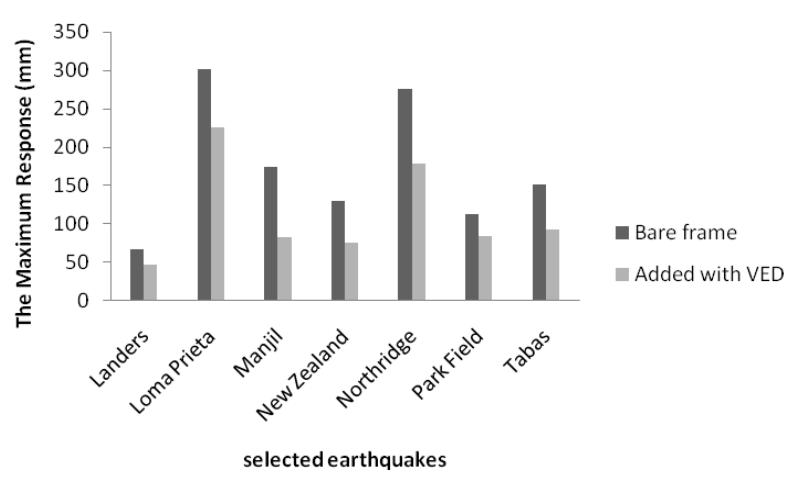

Fig. 7. Comparison of the top drifts for 5-story model.

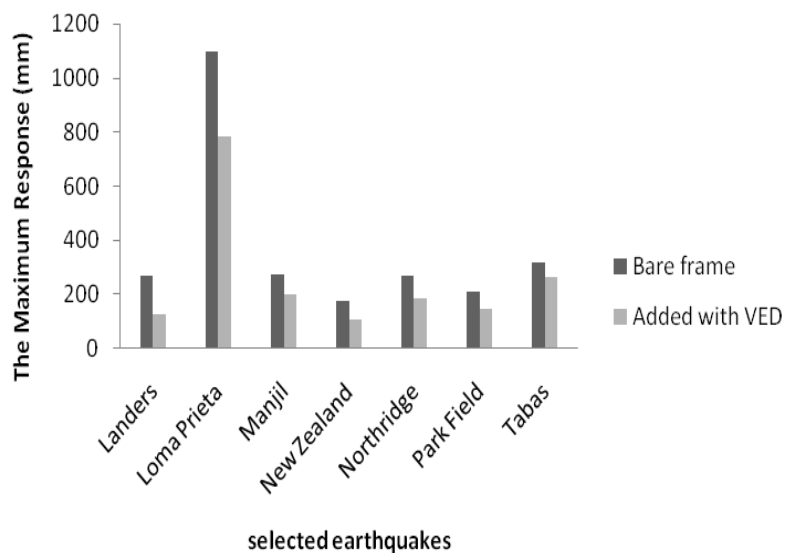

Fig. 8. Comparison of the top drifts for 10-story model.

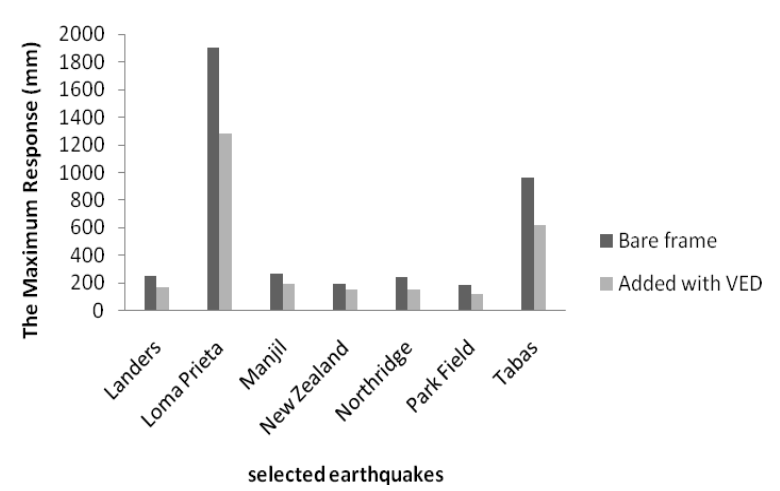

Fig. 9. Comparison of the top drifts for 15-story model.

A comparison of amounts of displacement in uncontrolled and controlled modes by inserting viscoelastic damper is shown in Tables above.

The results of the maximum roof displacement for the intended structures, indicating that the maximum story displacement of the roof for all three structures due to the added damper can be reduced on average so that viscoelastic damper can significantly reduce the seismic responses of structures against earthquakes. 


\section{CONCLUSIONS}

1) The computer package OpenSees is ideally suitable for conducting a time history analysis of structures with viscoelastic dampers.

2) The numerical results on three example frames clearly indicate that the viscoelastic dampers reduce the seismic response of structures in an extremely efficient way.

\section{ACKNOWLEDGMENT}

This Research was supported by Ahvaz branch of Islamic Azad University. The author also appreciates the editors and reviewers for their comments that lead to improve the quality of the paper.

\section{REFERENCES}

[1] R. H. Zhang and T. T. Soong, "Seismic design of viscoelastic dampers for structural applications," Journal of Structural Engineering ASEC , vol. 118, pp. 1375-92, 1992.

[2] P. Mahmoodi, "Structural dampers," Journal of Structural Devision, ASCE, vol. 95, no. 8, pp. 1661-72, 1969.

[3] R. H. Zhang, T. T. Soong, and P. Mahmoodi, "Seismic response of steel frame structures with added viscoelastic dampers," Earthq Eng Struct Dyn, vol. 18, pp. 389-96, 1989.

[4] K. C. Chang, T. T. Soong, S. T. Oh, and M. L. Lai, "Seismic response of a $2 / 5$ scale steel structure with viscoelastic dampers," Technical Report NCEER-91-0012. Buffalo, NY: National Center for Earthquake Engineering Research; 1991.

[5] R. C. Lin, Z. Liang, T. T. Soong, and R. H. Zhang, "An experimental study on seismic behavior of viscoelastically damped structures," Eng Struct, vol. 13, pp. 75-84, 1991.

[6] D. M. Bergman and R. D. Hanson, "Viscoelastic mechanical damping devices tested at real earthquake displacements," Earthq Spect, vol. 9, pp. 389-417, 1993.

[7] S. H. Lee, D. I. Son, J. Kim, and K. W. Min, "Optimal design of viscoelastic dampers using eigenvalue assignment," Earthq Eng Struct Dyn, vol. 33, pp. 521-42, 2004.

[8] P. Mahmoodi, "Design and analysis of viscoelastic vibration dampers for structures," in Proc. the WOVA-73 World Innovation Week Conference, 1974, pp. 25-39.
[9] C. J. Keel and P. Mahmoodi, "Designing of viscoelastic dampers for Columbia center building,, in building motion in wind," ASCE, New York, 1986, pp. 6682.

[10] K. C. Chang, K. L. Shen, T. T. Soong, and M. L. Lai, "Seismic retrofit of a concrete frame with added viscoelastic dampers," in Proc. the 5th Nat. Conference on Earthquake Engng, 1994.

[11] K. L. Shen, T. T. Soong, K. C. Chang, and M. L. Lai, "Seismic behavior of reinforced concrete frame with added viscoelastic dampers," Engng Struct, vol. 17, no. 5, pp. 372-80, 1995

[12] M. L. Lai, K. C. Chang, T. T. Soong, D. S. Hao, and Y. C. Yeh, "Full-scale viscoelastically damped steel frame," ASCE J Struct Engng, vol. 121, no. 1, pp. 1443-7, 1995.

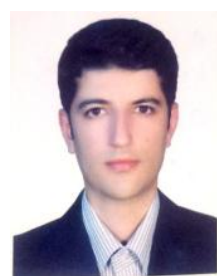

Ali Khoshraftar was born in Khorram Abad, Lorestan, Iran in 1979. He received his bachelor of science degree in civil engineering with a major in structural engineering from Isfahan University of Technology in Isfahan, Iran in 2003. He completed a master of science degree in civil engineering with a major in structural engineering from Iran University of Science and Technology in Tehran, Iran in 2005. He is a PhD student at the Faculty of Civil Engineering,

Islamic Azad University of Arak.

He was the head of Structural Department at general office of Khuzestan organization of schools from 2006 to 2009. Meanwhile, he was a master expert and engineer of seismic vulnerability evaluation of school buildings from 2008 to 2009. He has been an instructor in Civil Engineering Department of Islamic Azad University in Ahvaz, Iran since 2009. He became an associate dean of education in Engineering Department and the head of construction Department of Civil Engineering Department of Islamic Azad University in Ahvaz, Iran since 2010. He published an article entitled "The effect of degradation on seismic damage of RC buildings" in 8th International Conference on Civil and Architecture Engineering, Cairo, Egypt in 2010. His research interests are safety evaluation and retrofit of existing structures, Rehabilitation of structures and Durability and repair of concrete structures.

Mr. Khoshraftar is a member of Iranian Earthquake Engineering Association (IEEA), Iranian Society of Civil Engineers (ISCE) and Iranian Concrete Institute (ICI). He has a certificate in earthquake disaster management from Asian Disaster Reduction Center (ADRC) in cooperation with Japan International Cooperation Agency (JICA). He also holds a Rehabilitation of Existing Structures certificate from Iranian Earthquake Engineering Association (IEEA). 